NBER WORKING PAPER SERIES

\title{
DOES INFORMATION DISCLOSURE IMPROVE CONSUMER KNOWLEDGE? EVIDENCE FROM A RANDOMIZED EXPERIMENT OF RESTAURANT MENU CALORIE LABELS
}

\author{
John Cawley \\ Alex M. Susskind \\ Barton Willage \\ Working Paper 27126 \\ http://www.nber.org/papers/w27126
NATIONAL BUREAU OF ECONOMIC RESEARCH
1050 Massachusetts Avenue
Cambridge, MA 02138
May 2020

For their financial support, we are grateful to the Institute for the Social Sciences, the Institute for Healthy Futures, the Building Faculty Connections Program, the Cornell Center for Hospitality Research, and the College of Human Ecology at Cornell University. Cawley thanks the Robert Wood Johnson Foundation for an Investigator Award in Health Policy Research. For expert research assistance, we thank Katie Loshak, Julie Berman, Jenna Greco, Colin Wellborne, Julia Baker, and Miranda Miller. For their helpful cooperation with the study we thank Chefs Tony Vesco and Bob White, and instructors Chris Gaulke and Heather Kowalski. This experiment was approved by the Cornell IRB, protocol ID \# 1509005830. This study is registered in the AEA RCT Registry and the unique identifying number is: AEARCTR-0000940. The views expressed herein are those of the authors and do not necessarily reflect the views of the National Bureau of Economic Research.

At least one co-author has disclosed a financial relationship of potential relevance for this research. Further information is available online at http://www.nber.org/papers/w27126.ack

NBER working papers are circulated for discussion and comment purposes. They have not been peer-reviewed or been subject to the review by the NBER Board of Directors that accompanies official NBER publications.

(C) 2020 by John Cawley, Alex M. Susskind, and Barton Willage. All rights reserved. Short sections of text, not to exceed two paragraphs, may be quoted without explicit permission provided that full credit, including (C) notice, is given to the source. 
Does Information Disclosure Improve Consumer Knowledge? Evidence from a Randomized Experiment of Restaurant Menu Calorie Labels

John Cawley, Alex M. Susskind, and Barton Willage

NBER Working Paper No. 27126

May 2020

JEL No. D8,D83,H0,I1,I12,I14,I18,I24,K2,Q18

\begin{abstract}
The United States, in 2018, implemented a nationwide requirement that chain restaurants disclose calorie information on their menus and menu boards. This law was motivated by concern that consumers underestimate the number of calories in restaurant food, but it remains unclear the extent to which this information disclosure affects consumer knowledge. This paper fills that gap by estimating the impact of information disclosure on consumer knowledge through a randomized controlled field experiment of calorie labels on the menus of a full-service restaurant. The results indicate that information disclosure significantly reduces the extent to which consumers underestimate the number of calories in restaurant food; the labels improve the accuracy of consumers' post-meal estimates of the number of calories they ordered by 4.0 percent and reduces by $28.9 \%$ the probability of underestimating the calories in one's meal by $50 \%$ or more, both of which are statistically significant. However, even after information disclosure, there remains considerable error in consumer beliefs about the calorie content of the restaurant food they ordered. Even among the treatment group who received calorie labels, the average absolute value of percent error in their report is $34.2 \%$.
\end{abstract}

John Cawley

2312 MVR Hall

Department of Policy Analysis and Management and Department of Economics

Cornell University

Ithaca, NY 14853

and NBER

JHC38@cornell.edu

Alex M. Susskind

Statler Hall, Room 250

School of Hotel Administration

Cornell University

Ithaca, NY 14853

alex.susskind@cornell.edu
Barton Willage

2322 Business Education Complex South

Department of Economics

Louisiana State University

Baton Rouge, LA 70803

bwillage@1su.edu

A randomized controlled trials registry entry is available at AEARCTR-0000940 


\section{INTRODUCTION}

Economics has long been interested in how consumers respond to information (e.g. Stigler, 1961; Arrow, 1963; Pauly, 1968; Akerlof, 1970; Spence, 1973) and there is a large recent literature on how consumers interpret and react to information about health (e.g. Kim et al., 2019; Handel and Kolstad, 2015; Prina and Royer, 2014; Kolstad, 2013; Dupas, 2011; Pope, 2009; Jin and Leslie, 2009; Variyam, 2008; Dranove et al., 2003).

A common policy response to imperfect information by consumers is to require that producers disclose the missing information. However, it remains unclear to what extent the disclosed information improves consumers' knowledge of the products involved, in part because researchers rarely have data on consumers’ knowledge of disclosed information.

In this paper, we examine the accuracy of consumers' knowledge of how many calories they ordered in their restaurant dinner when the restaurant does not disclose calorie information, and the extent to which that consumer knowledge is improved by providing consumers with calorie labels on restaurant menus. A strength of this study is that the data were generated from a randomized experiment in which the treatment was the provision of calorie information on the menus in a real-world, full-service, restaurant. Another strength of the study is that we have data on consumer knowledge regarding the disclosed information. Consumers were asked after their meal how many calories they had ordered. By comparing the estimates of the treatment and control group we are able to estimate the impact of information disclosure on consumer knowledge.

Whether consumers have accurate information about the calorie content of their meals is important because the prevalence of obesity has risen dramatically in recent decades; in the U.S. it has nearly tripled over the past fifty years, rising from 13.4 percent in 1960-62 to 39.6 percent 
in 2015-16 (Fryar, Carroll, and Ogden, 2016; Hales et al., 2017). This is important for both public health and economic reasons because obesity raises the risk of numerous conditions such as heart attack, stroke, and diabetes (e.g. Hu, 2008; World Health Organization, 2000), and it is estimated that $\$ 190.2$ billion was spent treating obesity-related illness in U.S. adults in 2005 (Cawley and Meyerhoefer, 2012).

The causes of obesity are complex and multi-factorial (see, e.g. Cawley, 2015) but one possible contributor to the rise in obesity is Americans eating an increasing amount of their food away from home (e.g. in restaurants), and that they tend to underestimate the number of calories in the restaurant meals that they order. The percentage of calories consumed in the form of food away from home has roughly doubled, from 18 percent in 1977-78 to 34 percent in 2004-05 (Saksena et al., 2018). Since 2010, Americans spend more on food away from home than they spend on food at home (e.g. purchases from grocery stores and food retailers) (Elitzak and Okrent, 2018). ${ }^{3}$ This is relevant for obesity because food away from home has been found by the USDA to be "consistently lower quality and more caloric" than food at home (Saksena et al., 2018, p. 2).

Evidence suggests that consumers tend to underestimate the calorie content of restaurant food (An, 2016; Stewart et al., 2014; Block et al., 2013). This is true even for well-educated and well-informed people; for example, one study surveyed dieticians attending the American Dietetic Association annual meeting, and asked them to estimate the number of calories in takeout food from major restaurant chains. Despite being shown all of the food items, the 256 surveyed dieticians underestimated the calories in each item by an average of 28- $48 \%$ depending

\footnotetext{
${ }^{3}$ Obviously, the amount of food consumed away from home has temporarily fallen during the COVID-19 pandemic.
} 
on the food item (Backstrand et al, 1997). Thus, even trained professionals in the field of diet and nutrition tend to substantially underestimate the number of calories in food away from home.

Given peoples’ tendency to underestimate the number of calories in restaurant food, numerous organizations endorsed requiring calorie counts on restaurant menus (e.g. American Heart Association, 2009; Institute of Medicine, 2005, 2012), and a nationwide requirement for such menu labels took effect in the U.S. in 2018. However, it remains unclear to what extent these calorie labels have improved consumers' knowledge of the number of calories they order.

It is unclear how consumers react to calorie information on menus. Calorie labels might provide important new information that dramatically improves patrons' knowledge of the number of calories that they order. However, there are other possibilities. Patrons might fail to notice the labels if the labels are not salient (e.g. Bordalo et al., 2013). Even if consumers notice the calorie information they might deliberately choose to ignore it, a phenomenon known as strategic self-ignorance (Thunstrom et al., 2016) or information aversion (Andries and Haddad, 2020); this could occur if patrons feel that they would enjoy their meal more if they didn't know its calorie content. Another possibility is that consumers notice the information, but, due to bounded rationality, are unable to fully comprehend or use it (e.g. Rice, 2013; Simon, 1955). It is also possible that consumers already had accurate beliefs about the number of calories in restaurant food, and thus labels do not provide any new information; this seems unlikely, however, given that people tend to underestimate the number of calories in restaurant food (e.g. Backstrand et al, 1997; Block et al., 2013).

In this paper, we ask and answer three important research questions: 1) How accurately do consumers know the number of calories they have ordered if the restaurant menu did not have calorie labels? In particular, do people tend to underestimate the number of calories in restaurant 
food? 2) Are education, or other characteristics, associated with greater knowledge of the calorie content of restaurant food? 3) Does the provision of calorie information on restaurant menus improve consumer knowledge of the number of calories they ordered at that meal? We answer these questions using data from a randomized controlled experiment we conducted in a realworld restaurant in which the control group received menus without calorie labels, and the treatment group received menus with calorie labels.

Several studies have examined whether exposure to menu labels improves consumers' knowledge of the number of calories they have ordered. ${ }^{4}$ One study (Roberto et al., 2010) is based on a randomized controlled experiment of calorie labels, although it takes place in a lab environment rather than an operating restaurant. Meals were provided free of charge, so subjects may not have responded as they would in the real world (e.g. several subjects ordered two entrees). The study also had a small sample size ( $\mathrm{N}=303$, all of whom were residents of New Haven, CT). Another limitation is that for one of the two restaurants that provided food, the researchers did not know the calorie counts of the food or the recipes so they estimated the number of calories in the meals from that restaurant. The authors found that the control group that was not provided calorie labels underestimated the calorie content of their meal by $32.6 \%$, which is significantly greater than the $25.0 \%$ underestimation by the treatment group that received the menu labels and a statement of the recommended daily calorie intake.

Two other studies have used non-experimental methods to estimate the impact of calorie labels on consumer knowledge; both estimated difference-in-differences (DiD) models comparing patrons in cities that enacted menu label laws to patrons in comparison communities.

\footnotetext{
${ }^{4}$ Other research has examined the impact of calorie labels on the number of calories ordered; the results indicate a small reduction in calories ordered in full-service restaurants (Cawley, Susskind, and Willage, forthcoming) and coffeeshops (Bollinger et al., 2011) and no detectable change in calories ordered in fast food restaurants (Elbel et al., 2009; Cantor et al., 2015).
} 
Elbel (2011) exploited New York City's menu label law, and compared patrons there to patrons in the comparison city of Newark. All subjects $(\mathrm{N}=1,147)$ were intercepted while patronizing fast food restaurants in low-income areas, and were asked how many calories they had ordered, which was compared to their receipts. The DiD estimate is that calorie labels reduced the error in patrons' estimates of the number of calories that they ordered by 36 calories, which is not statistically significant. The author also created an indicator variable for whether the patron's report was within 100 calories in either direction of the true amount; exposure to the labels increased the probability of such accuracy by 15 percentage points; however, the accuracy of the treatment group increased by 9 percentage points and that of the control group fell by 5 percentage points, so not all of that change may be due to the law.

Taksler and Elbel (2014) conducted a similar study but estimated the effect of Philadelphia’s menu label law relative to the comparison city of Baltimore. All subjects $(\mathrm{N}=1,835)$ were intercepted while patronizing McDonald's or Burger King in low-income areas. The $\mathrm{DiD}$ estimates suggest that calorie labels improved accuracy by 122 calories (which was due more to the control group becoming less accurate by 114 calories than to the treatment group becoming more accurate by 63 calories); this $\mathrm{DiD}$ estimate was not statistically significant. For both Elbel (2011) and Taksler and Elbel (2014), the standard errors are likely underestimated, because the data consist of one treated cluster and one control cluster, but the estimates are not clustered by geography (Donald and Lang, 2007; Cameron and Miller, 2015).

Our study contributes to the literature by estimating the impact of calorie labels on consumer knowledge by conducting a randomized controlled trial which has over five times more subjects $(\mathrm{N}=1,546)$ than the previous study to conduct an RCT on this topic (Roberto et al., 2010, which had $N=303$ ). As a result, we have greater statistical power. Other advantages of this 
study relative to the previous RCT are that ours takes place in a real restaurant rather than a lab setting, and we have accurate calorie information for all of the restaurant food and beverages in question. Relative to the papers taking a DiD approach using city-level label laws, we are able to conduct a randomized experiment, which has fewer concerns about omitted variables bias than using policy variation, and we are able to cluster at the level of randomization or policy variation (in our case, party, in their case, city); which improves the accuracy of the standard errors.

\section{METHODS AND DATA}

We conducted a randomized controlled field experiment of calorie labels on menus at a sit-down, full-service restaurant. ${ }^{5}$ The restaurant is located in a hotel on a college campus, has 38 tables, serves all meals (although we conducted the experiment only during dinner), and is open seven days a week.

Randomization occurred at the level of party (i.e., the table); it was undesirable to randomize at the level of individual guest because parties might discuss the menu while at the table. Upon checking in with the maître d', each dining party was randomized to either the treatment or control group using a smartphone app. The control group received the usual set of menus (which had no calorie information), and the treatment group received the same menus but with the addition of calorie labels. ${ }^{6}$ The nationwide law in the U.S. that requires calorie labels on restaurant menus applies only to chains of 20 or more restaurants doing business under the same

\footnotetext{
${ }^{5}$ The dates of the experiment in this restaurant were May 12, 2016 to September 30, 2017. This was part of a larger project in which we also conducted a randomized experiment of restaurant menu calorie labels at a second restaurant. Data from that second restaurant is not used here because those patrons were not asked to estimate the number of calories they had ordered. Our estimates of the impact of calorie labels on the number of calories ordered are available in Cawley, Susskind, Willage (forthcoming).

${ }^{6}$ The calorie counts were calculated using the software MenuCalc, which uses the USDA's nutritional database of 18,000 ingredients and accounts for the loss of nutrients due to cooking methods. MenuCalc was also the source for the calories in the cocktails; the calories for other beverages (e.g. wine, beer, and soda) were taken from manufacturer labels or websites.
} 
name; our study restaurant is independent and thus is exempt from the law. As a result, we are able to legally have a control group who received menus without calorie information.

The menu items during the time of this study were chosen by the restaurants; the researchers played no role in selecting what would be offered. Thus, the menus were not artificially generated by the study, instead they are a real-world set of options from the field. The restaurant periodically changed its menu; the treatment menu was always updated with accurate calorie information to account for such changes.

Data on orders placed by each guest were recorded by the server and entered into the restaurant's point of sales system. Each guest was assigned a unique number corresponding to their seat at that table so we could maintain an accurate record of each guest's order throughout the entire meal. The servers also noted which food and beverages were to be split by certain guests or shared by the entire table (the calories for these items were assumed to be divided equally between all patrons who shared).

At the conclusion of the meal, a research assistant approached the table and asked each guest to complete a survey. The survey asked for their demographic information (including age, race, ethnicity, sex, and educational attainment) and also asked them to report the number of calories they had ordered. ${ }^{7}$ Completed surveys were stapled to the record of each guest's order, and these data were later entered electronically. The experiment was approved by the Cornell IRB, protocol ID \# 1509005830.

Our final analysis sample consists of $\mathrm{N}=1,546$ patrons. Figure 1 is the recruitment flow chart that lists the exclusion criteria and detailed information regarding sample sizes. Patrons were assigned either to the treatment group $(T=2,125)$ or the control group $(C=2,062)$. We

\footnotetext{
${ }^{7}$ The wording of the question was: "How many calories do you think your meal (including beverages) contained tonight?”
} 
dropped those who ordered zero calories $(\mathrm{N}=66 ; \mathrm{T}=34, \mathrm{C}=32)$. We dropped from the analysis all patrons who are on return visits to the restaurant since the study began ( $N=524 ; \mathrm{T}=271$; $\mathrm{C}=253$ ); the concern is that people on their return visit may remember the treatment from their first visit. Thus, the analysis sample consists entirely of people on their first visit to the restaurant since the study began. In addition, N=599 ( $\mathrm{T}=307, \mathrm{C}=292)$ were dropped for being minors or non-English speakers. For the sake of consistency and comparability we limit the sample to those who had a dinner; for this reason we drop N=191 ( $\mathrm{T}=95, \mathrm{C}=96$ ) because they did not order an entrée. We are left with data on food orders for 2,807 individuals $(T=1,417 ; \mathrm{C}=1,390)$.

Of those 2,807 patrons, 568 ( $\mathrm{T}=289 ; \mathrm{C}=279$ ) refused to participate in the survey after their meal. Of the remaining $\mathrm{N}=2,239$ individuals $(\mathrm{T}=1,128 ; \mathrm{C}=1,111), \mathrm{N}=689$ ( $\mathrm{T}=317 ; \mathrm{C}=372)$ did not provide estimates of calories ordered. We also dropped four observations for reporting estimated calories that were extreme outliers: two were extremely low (12 and 30) and two were extremely high $(10,000$ and 15,000). Three of those outliers were in the treatment group and one was in the control group. Obviously, in a study of the accuracy of people's beliefs it is challenging to know whether an outlier represents the person's true belief or might have simply been a transcription error. Given how far these outliers are from the next reports (the next lowest is 100 and the next highest is 5,000) we think it most likely that this represents transcription error rather than a true belief. Overall, we have data on both orders and estimated numbers of calories ordered for 1,546 individuals ( $\mathrm{T}=808$; $\mathrm{C}=738$ ).

Using these data, we first examine the accuracy of the reports of calories ordered by the control group, who received no calorie information. We calculate this accuracy several ways: absolute value of raw error, the absolute value of percent error, and categories for direction and magnitude of error (e.g. underestimate by $10 \%$ or more). We also estimate regressions of 
accuracy, in which we regress each measure of error on demographic and other characteristics of the patron. In particular, we test whether better-educated individuals exhibit greater accuracy or knowledge of their calories ordered.

Using the data collected in our randomized field experiments, we estimate the effect of calorie labels on consumer knowledge using regression models of the following form:

$$
Y_{i}=\alpha+\beta T_{i}+\gamma X_{i}+\varepsilon_{i}
$$

where $Y$ is a measure of calorie knowledge for consumer $i$. $T$ is an indicator variable for random assignment to the treatment group. $X$ is a vector of controls and includes age, sex, race, and education. We also control for indicator variables for day of the week because people may behave differently on certain nights (e.g. patrons and dinners on Fridays might be different than those on Mondays). We also control for indicator variables for month-by-year to address any seasonality in decision-making. We also control for indicator variables for table of the restaurant and seat number to control for any possible differences in environment (e.g. amount of light, proximity to the kitchen, or visibility to other patrons). We also control for indicator variables for server because people may pay differential amount of attention to the menu based on their server. The model also includes indicator variables for missing data for the regressors taken from the survey: sex, age, race, ethnicity, and education. The variable $\varepsilon$ is an error term. We cluster standard errors at the level of party because that is the level of randomization, and errors may be correlated within party. We estimate the equation using ordinary least squares for continuous outcomes, and linear probability models for binary outcomes.

We also test whether better-educated individuals were more greatly affected by the information disclosure; to do so we add to the equation above an interaction of the treatment indicator $T$ with an indicator variable for being in the highest-education group. 


\section{EMPIRICAL RESULTS}

\section{Summary Statistics}

Table 1 presents summary statistics for descriptive characteristics of the sample, overall as well as separately for the treatment and control group. Overall, the sample $(\mathrm{N}=1,546)$ is $45.6 \%$ male, and averages 41.3 years old. The sample is $73.0 \%$ white, $18.7 \%$ Asian, and $8.3 \%$ other race; $6.5 \%$ of the sample is Hispanic. It is also a well-educated sample; $45.3 \%$ of patrons have a graduate degree, $25.7 \%$ have a college degree and/or are current graduate students, $17.6 \%$ are currently college students, and $11.3 \%$ have less than a college degree. Clearly, higher percentages of the sample are Asian, and are college-educated, than the US population as a whole ${ }^{8}$; in general a limitation of randomized experiments is that they happen in one or a few locations, which can be a challenge for generalizability (e.g. Deaton and Cartwright, 2018). While this should be kept in mind when interpreting the results and generalizing to larger samples, randomized experiments are still seen as a vitally important method for estimating causal effects (e.g. Remler \& Van Ryzin, 2014; Shadish, Cook, and Campbell, 2002).

Table 1 also presents summary statistics for the treatment and control groups separately, and results of balance tests of whether the characteristics of the two groups are significantly different. For almost all characteristics, there are no significant differences between the treatment and control group; the exception is that the average party size in the treatment group was slightly

\footnotetext{
${ }^{8}$ The most recent Census data for the U.S. indicates that the U.S. population in 2018 was $76.5 \%$ white, $13.4 \%$ African-American, 5.9\% Asian, and 1.5\% Native American (including Hawaiian), and an additional 2.7\% reporting two or more races. In terms of ethnicity, $18.3 \%$ were Hispanic or Latino. In terms of the educational attainment of the U.S. population aged 25 years or older, $58.9 \%$ had less than a college degree, $28.6 \%$ had a college degree (bachelor's or associates degree), and 12.6\% had a graduate degree. See U.S. Census (2020a, 2020b).
} 
larger (by 0.36 of a patron). There are no significant differences in sex, age, race, or education between the treatment and control groups.

Table 2 presents summary statistics of the outcomes. For the sample as a whole, patrons ordered an average of 1,308 calories, but after the meal they estimated, on average, that they had ordered 1,093. On average, the absolute value of the error in the estimated number of calories ordered was 465 , or $35.8 \%$ of their true order.

\section{Consumers Underestimate the Calories in Restaurant Food}

To test whether consumers underestimate the calories in restaurant food, we examined the accuracy of patron's estimates of the number of calories ordered, only for the control group, who had no calorie information on their menus. Table 3, Panel A, presents descriptive statistics for the control group alone. On average, consumers in the control group ordered 1,341 calories but reported that they ordered 1,080.

To some extent, raw errors cancel each other out - those overestimating the number of calories in their meal cancel out those who underestimate them. For this reason, we examine the absolute value of error. Among the control group (who had no calorie information on their menus), the average absolute value of error was 497 calories. The average across consumers of the absolute value of their percent error was $37.7 \%$.

The majority of the control group (59.9\%) underestimated the number of calories in their order by at least $10 \%, 44.6 \%$ underestimated the calories in their order by at least $25 \%$, and $14.4 \%$ underestimated the calories in their order by $50 \%$ or more. Twenty-four percent 
overestimated the number of calories in their order by more than $10 \%$, and $15.6 \%$ of the control group gave an estimate that was within $10 \%$ of the actual number of calories ordered. ${ }^{9}$

In summary, it is clear that, in the absence of the disclosure of calorie information, consumers do not have accurate beliefs about the calorie content of restaurant food. The average percent absolute value of error is $37.7 \%$, the clear majority (59.9\%) of consumers underestimate the number of calories they ordered by at least $10 \%$, and $14.4 \%$ underestimated the calories in their order by $50 \%$ or more.

\section{Extent of Underestimation Rises with Actual Number of Calories Ordered}

Figure 2 shows the distribution of actual ordered calories (dark bars) and the distribution of patrons' estimates of their number of calories ordered (white bars). The histograms indicate that the distribution of estimated calories ordered has a lower mean and is less right-skewed than the distribution of calories actually ordered.

In order to show the within-person difference between the actual calories ordered and their estimate of their calories ordered, Figure 3 plots raw error over actual calories ordered. ${ }^{10}$ The pattern shows a negative slope - those who ordered more calories tend to underestimate their number of calories ordered to a greater degree. A small percentage of people who ordered under 1,000 calories actually overestimate how many calories they ordered, but the vast majority of patrons underestimate the number of calories they ordered, and the amount by which they underestimate it rises with the actual number of calories they ordered.

\footnotetext{
${ }^{9}$ Ten subjects ( $0.65 \%$ of the sample) gave an estimate of the calories ordered that exactly matched the number of calories ordered. Those ten people were evenly divided between the treatment and control group (5 in each).

${ }^{10}$ In Figure 3 and Figure 4, bin sizes for "Actual Calories Ordered" are in 100-calorie increments, such as from 700799 calories. There are 429 unique values for Actual Calories Ordered.
} 
Figure 4 plots percent raw error over actual calories ordered, and shows that, even in percentage terms, the degree of under-estimation rises with the actual number of calories ordered. Those who order the most calories (roughly 2,500 or more) tend to underestimate the number of calories in their meal by $50 \%$ or more.

\section{People See the Disclosed Information}

Although everyone in the treatment group was given a menu containing calorie labels, not everyone may have seen that information. Some people may have ordered without looking at the menu or may have looked at the menu but not noticed the calorie labels. To investigate this, we asked on the post-meal survey: "Do you recall seeing any calorie information in this restaurant on the menus TONIGHT during your meal?” The vast majority of the treatment group (82.6 percent) reported seeing calorie information, but so did 15.6 percent of the control group. We estimate a model of reporting having seen calorie information on an indicator variable for being randomized to the treatment group and other regressors. We estimate the model with three increasingly large sets of regressors: one that controls for nothing other than an indicator for treatment, a second that also controls for party size and indicators for day of week, month, table, seat, and server; and a third model which controls for all of those variables plus gender, age, Hispanic, race, and education. Results across the three models tend to be similar, so throughout the paper we will focus on the results of model 3, which includes the most controls.

The results in Table 4 indicate that being randomized to the treatment group increases by 68.8 percentage points (136\%) the probability of reporting, after the meal, that one saw calorie information on the restaurant menu. These results are consistent with the vast majority of consumers seeing the disclosed information. 


\section{Calorie Labels Improve Consumer Knowledge}

Table 5 lists the results of our regression models that estimate the impact on information disclosure on consumer knowledge. Specifically, we estimate the effect of calorie labels on the accuracy of one's knowledge, which is measured three ways: 1) the absolute value of error in the estimate; 2) the absolute value of percent error in the estimate; and 3) categories for direction and magnitude of error (e.g. underestimate by more than $50 \%$ ).

The results in Table 5 show that being randomized to the treatment group and thus being exposed to the calorie labels is associated with more accurate knowledge of the number of calories ordered. Specifically, calorie labels improve the accuracy of consumers' post-meal estimates by 64.7 calories or 4.0 percentage points.

Those represent average treatment effects. We also examine how the disclosure of information affects the category of patron error. The results are provided in Table 6A and 6B. Providing calorie labels on restaurant menus decreases the probability that consumers greatly underestimate the calories in their meal. Specifically, calorie labels reduce the probability of underestimating the calories in one's meal by $50 \%$ or more by 3.7 percentage points (28.9\%) and reduces the probability that one underestimates the calories in one's meal by $25-49.9 \%$ by 5.7 percentage points (20.6\%). Calorie labels increase the probability that the consumer accurately reports the number of calories they ordered (i.e. has less than $10 \%$ error) by 3.9 percentage points (23.1\%). However, it also significantly increases the probability of overestimating the number of calorie's in one's meal by $25-49 \%$ by 5.8 percentage points (66.6\%).

Those categories reflect the direction as well as the magnitude of error. If one does not care about direction but only about magnitude, we provide estimates of the impact on the 
magnitude of the absolute value of error in Table 6B. Calorie labels reduce the probability of the consumer's error being 50\% or larger by 5.7 percentage points (25.1\%) and increases the probability that the error is in the range of $5-24 \%$ by 4.9 percentages points (15.3\%). Not all measures of accuracy are significantly impacted by calorie labels, however; the probability that the report met the narrowest definition of accuracy (being within $5 \%$ of the true value) was raised by 1.1 percentage points, but this is not statistically significant.

In summary, calorie labels on restaurant menus significantly reduce the probability that consumers greatly underestimate the number of calories in their order.

\section{Men Have Less Accurate Information Than Women}

We also investigate which groups tend to report more accurately. Table 7 reports coefficients from the regressions estimating the treatment effect of calorie labels; all estimates are taken from what was previously called "model 3," which includes the most control variables. The results indicate that men tend to report less accurately than women - by an average of 64.4 calories in absolute value. Put another way, men's reports are less accurate by an average of $2.8 \%$ absolute value of error. One possible explanation for this is that men are less likely to notice the calorie information on the menu. Table 7, column 1, indicates that men are 5.7 percentage points less likely to report seeing the calorie information, which is statistically significant at the $5 \%$ level.

\section{No Differential Treatment Effect by Education}

In order to test whether better-educated people learn more from calorie labels, we estimate models of accuracy that are the same as before but add an interaction term between the treatment 
indicator and an indicator variable for having a less than a college degree. The results, shown in Tables 8A, 8B, and 8C, yield no evidence that people with less education are less affected by calorie labels. Table 8A shows the differential impact of calorie labels by education when the outcome is the absolute value of error, and the absolute value of percent error; Table 8B shows the impact on various categories of the sign and direction of error; and Table 8C shows the impact on various categories of the absolute value of the magnitude of error. In no case is the interaction between the treatment indicator and the indicator for less education statistically significant. However, we caution that the results are imprecise and the 95\% confidence intervals contain meaningfully-sized estimates. We also caution that a limitation of this analysis is that we have a relatively highly educated sample, so only $11.3 \%$ of our sample has less than a college education.

\section{Even with Information Disclosure, Considerable Error Remains}

The earlier results presented in this paper indicate that information disclosure, in the form of calorie labels on restaurant menus, significantly improves consumer knowledge of the number of calories they ordered. In this sub-section, we next examine the extent of error that remains after information disclosure.

Examining the treatment group alone in Table 3, Panel B, we see that error remains substantial. Among the treatment group, to whom calorie information was disclosed, the error in the post-meal estimate is equal to 436 calories in absolute value, or an absolute value of percent error of 34.2\%. Even though everyone in the treatment group was given the calorie labels, the majority (52.4\%) underestimate the calories in their meal by $10 \%$ or more, $29.4 \%$ overestimate it by $10 \%$ or more, and just $18.1 \%$ are correct within $10 \%$ of the true value. All of these are 
statistically significant at the $1 \%$ level. Thus, even though calorie labels improve consumer knowledge, considerable error remains.

\section{DISCUSSION}

A premise of the nationwide law requiring the disclosure of calorie information on restaurant menus is that these labels will improve consumer knowledge about the number of calories in restaurant food; if they do not, then the policy is unlikely to change consumers' ordering behavior, or to lead to later offsetting behavior in the form of fewer calories consumed in subsequent meals, or increased exercise.

We estimate the effect of information disclosure on consumer knowledge; specifically, the effect of restaurant menu calorie labels on consumer knowledge about the calorie content of their order. We estimate this by conducting a randomized controlled field experiment in a fullservice restaurant. By surveying patrons after their meal and asking them to report how many calories they ordered, we have rare data on consumer knowledge of the disclosed information.

Several important conclusions emerge from the results. First, in the absence of information disclosure, consumers tend to underestimate the number of calories in restaurant food. Among the control group (who had no calorie information on their menus), the average absolute value of their percent error was 37.7\%. The clear majority of the control group (59.9\%) underestimated the number of calories in their order by more than $10 \%, 44.6 \%$ of them underestimated the calories in their order by $25 \%$ or more, and $14.4 \%$ of them underestimated the calories in their order by $50 \%$ or more.

Second, the extent to which consumers underestimate the number of calories in their order rises with the actual number of calories ordered; this is true for both the raw error and the 
percent error. Third, we estimate that being provided menu labels increases the probability that consumers later report seeing the calorie information by 68.8 percentage points or $136 \%$. Thus, the vast majority of consumers do notice the disclosed information.

Fourth, we find that information disclosure in the form of restaurant menu calorie labels significantly improves consumer knowledge of the number of calories they ordered. Specifically, the labels improve the accuracy of consumers’ post-meal estimates by 64.7 calories or 4.0 percentage points. Put another way, calorie labels reduce the probability of underestimating the calories in one’s meal by $50 \%$ or more by 3.7 percentage points (28.9\%) and increase the probability that the consumer correctly reports the number of calories they ordered (less than $10 \%$ error) by 3.9 percentage points (23.1\%).

Fifth, even after information disclosure, considerable error remains. Among the treatment group, the error in the post-meal estimate is equal to 436 calories in absolute value, or an absolute value of percent error of 34.2\%. Even among the treatment group, the majority of consumers (52.4\%) continue to underestimate the calories in their meal by $10 \%$ or more.

This paper is informative about the impact of the 2018 nationwide menu label law in the U.S. Specifically, our estimates suggest that the requirement has achieved the public health goal of reducing the extent to which consumers underestimate the number of calories in their restaurant meals, but at the same time there remains considerable inaccuracy in consumers’ knowledge of how many calories they ordered. In other words, the 2018 menu label requirement may have reduced but not eliminated the information asymmetry in the market for restaurant food, which is where Americans spend the majority of their food expenditures.

One unexpected result is that the calorie labels increase by 5.8 percentage points $(66.7 \%)$ the probability that consumers overestimate the number of calories ordered by $25-49 \%$. It is 
important to note, though, the overall effect of the calorie labels is to improve consumer knowledge. When models are estimated using the absolute value of error, calorie labels reduce, by 5.7 percentage points (25.1\%) the probability of the highest category of error (an absolute value of error of $50 \%$ or more). Labels also increase, by 4.9 percentage points (15.3\%) the probability of more modest error (5-24\% in absolute value). Still, it is noteworthy that information disclosure leads some people to be less accurate in their beliefs.

By estimating the impact of information disclosure on consumer knowledge in one important market, this paper contributes to the literature of how consumers interpret and use health-related information (e.g. Kim et al., 2019; Prina and Royer, 2014; Dupas, 2011; Pope, 2009; Variyam, 2008; Jin and Leslie, 2004; Dranove et al., 2003).

This study has a number of limitations. First, as is usually the case with randomized experiments, we have a select group of subjects, which limits generalizability (Shadish, Cook, and Campbell, 2002; Remler and Van Ryzin, 2014; Deaton and Cartwright, 2018). This study took place at a restaurant that is located on a college campus, which has implications for generalizability. For example, our sample is relatively highly educated. On the one hand, people with higher education may be better able to use health-related information (Grossman, 1972), and thus we might expect to see a greater treatment effect. On the other hand, a well-educated sample may already be well-informed about the calorie content of food and thus calorie labels may provide less new information for them, and thus there could be a smaller treatment effect. However, we find that even our well-educated sample tends to report their number of calories ordered with considerable error, even after being provided with calorie information on the menu. Moreover, we do not find any significant difference in the error across education categories, nor 
can we reject the null hypothesis of equal treatment effects for those of low education and those of higher education.

The data used in this paper come from an experiment conducted at one restaurant. Much can be learned from data from one or two firms (e.g. Royer, Stehr, and Sydnor, 2015; Charness and Gneezy, 2009; Finkelstein and Poterba, 2004) or from one location (e.g. Finkelstein et al., 2012). Still, it would be helpful to conduct this experiment at additional restaurants; the accuracy of people's beliefs about the calorie content of restaurant food, and the effect of calorie labels on those beliefs, may depend on the set of food items on the menu.

Another important area for future research is determining how to present and convey information so that consumers can easily interpret and use it. For example, it has been proposed that instead of posting calorie counts, restaurant menus could instead list the distance one would have to walk to burn that amount of energy (Dowray et al., 2013), which may make the information more salient. In other health contexts, researchers have found that people may comprehend information better when it is conveyed using symbols such as stars rather than raw numbers (Barnes et al., 2012). Applying the tools of behavioral economics to the provision of information may help ensure that information disclosure improves consumer knowledge to the greatest possible extent. 


\section{Works Cited}

Akerlof, G. A. (1970). The market for "lemons": Quality uncertainty and the market mechanism. Quarterly Journal of Economics, 84, 488-500.

American Heart Association. 2009. Policy Position Statement on Menu Labeling (June 2009) http://www.heart.org/idc/groups/heartpublic/@wcm/@adv/documents/downloadable/ucm_301652.pdf

An, R. (2016). Fast-food and full-service restaurant consumption and daily energy and nutrient intakes in US adults. European Journal of Clinical Nutrition, 70, 97-103.

Andries, M., \& Haddad, V. (2020.) Information aversion. Journal of Political Economy, forthcoming. https://doi.org/10.1086/705668

Arrow, K. J. (1963). Uncertainty and the welfare economics of medical care. American Economic Review, 53, 941-973.

Backstrand J., M. Wootan, L. Young, and J. Hurley. 1997. Fat Chance. Center for Science in the Public Interest, Washington, DC, 1997. http://portionteller.com/pdf/cspistudy97.pdf

Barnes, A. J., Hanoch, Y., Wood, S., Liu, P. J., \& Rice, T. (2012). One fish, two fish, red fish, blue fish: Effects of price frames, brand names, and choice set size on Medicare Part D insurance plan decisions. Medical Care Research and Review, 69(4), 460-473.

Block, J.P., Condon, S.K., Kleinman, K., Mullen, J., Linakis, S., Rifas-Shiman, S., \& Gillman, M.W. (2013). Consumers' estimation of calorie content at fast food restaurants: Cross sectional observational study. BMJ, 346, f2907.

Bollinger, B., Leslie, P., \& Sorensen, A. (2011). Calorie posting in chain restaurants. American Economic Journal: Economic Policy, 3, 91-128.

Bordalo, P., Gennaioli, N., \& Shleifer, A. (2013.) Salience and consumer choice. Journal of Political Economy, 121, 803-843.

Cameron, A. C., \& Miller, D. L. (2015). A practitioner’s guide to cluster-robust inference. Journal of Human Resources, 50, 317--372.

Cantor, J., Torres, A., Abrams, C., \& Elbel, B. (2015). Five years later: Awareness of New York City's calorie labels declined, with no changes in calories purchased. Health Affairs, 34, 1893-1900.

Cawley, J. (2015). An economy of scales: A selective review of obesity's economic causes, consequences, and solutions. Journal of Health Economics, 43, 244-268.

Cawley, J., \& Meyerhoefer, C. (2012). The medical care costs of obesity: An instrumental variables approach. Journal of Health Economics, 31, 219-230.

Cawley, John, Alex Susskind, and Barton Willage. Forthcoming, 2020. "The Impact of Information Disclosure on Consumer Behavior: Evidence from a Randomized Field Experiment of Calorie Labels on Restaurant Menus.” Journal of Policy Analysis \& Management.

Charness, G., \& Gneezy, U. (2009). Incentives to exercise. Econometrica, 77, 909-931.

Deaton, A., \& Cartwright, N. (2018). Understanding and misunderstanding randomized controlled trials. Social Science \& Medicine, 210, 2-21.

Donald, S. G., \& Lang, K. (2007). Inference with difference-in-differences and other panel data. Review of Economics and Statistics, 89, 221-233. 
Dowray, S., Swartz, J.J., Braxton, D., \& Viera, A.J. (2013). Potential effect of physical activity based menu labels on the calorie content of selected fast food meals. Appetite, 62, 173181.

Dranove, D., Kessler, D., McClellan, M., \& Satterthwaite, M. (2003). Is more information better? The effects of "report cards" on health care providers. Journal of Political Economy, 111, 555-588.

Dupas, P. (2011). Do teenagers respond to HIV risk information? Evidence from a field experiment in Kenya. American Economic Journal: Applied Economics, 3, 1-34.

Elbel, B., Kersh, R., Brescoll, V.L., \& Dixon, L.B. (2009). Calorie labeling and food choices: A first look at the effects on low-income people in New York City. Health Affairs, 28, w1110-w1121.

Elbel, B. (2011). Consumer estimation of recommended and actual calories at fast food restaurants. Obesity, 19, 1971-1978.

Elitzak, Howard, and Abigail Okrent. 2018. "New U.S. Food Expenditure Estimates Find FoodAway-From-Home Spending Is Higher Than Previous Estimates.” Amber Waves, November 5. U.S. Department of Agriculture. https://www.ers.usda.gov/amberwaves/2018/november/new-us-food-expenditure-estimates-find-food-away-from-homespending-is-higher-than-previous-estimates/

Finkelstein, A., \& Poterba, J. (2004). Adverse selection in insurance markets: Policyholder evidence from the UK annuity market. Journal of Political Economy, 112, 183-208.

Finkelstein, A., Taubman, S., Wright, B., Bernstein, M., Gruber, J., Newhouse, J. P., ... \& Oregon Health Study Group. (2012). The Oregon health insurance experiment: Evidence from the first year. Quarterly Journal of Economics, 127, 1057-1106.

Fryar, C. D., Carroll, M. D., \& Ogden, C. L. (2016). Prevalence of overweight, obesity, and extreme obesity among adults aged 20 and over: United States, 1960-1962 through 2013-2014. National Center for Health Statistics Health E-Stats, 1-6. Available at https://www.cdc.gov/nchs/data/hestat/obesity_adult_13_14/obesity_adult_13_14.pdf.

Grossman, M. (1972). The Demand for Health: A Theoretical and Empirical Investigation. New York, NY: NBER Books.

Hales C. M., Carroll M. D., Fryar C. D., \& Ogden, C. L. (2017). Prevalence of obesity among adults and youth: United States, 2015-2016. NCHS Data Brief, 288. Hyattsville, MD: National Center for Health Statistics.

Handel, B. R., \& Kolstad, J. T. (2015). Health insurance for" humans": Information frictions, plan choice, and consumer welfare. American Economic Review, 105(8), 2449-2500.

Hu, F. (2008). Obesity Epidemiology. New York, NY: Oxford University Press

Institute of Medicine. (2005). Preventing Childhood Obesity: Health in the Balance. Washington, DC: National Academies Press.

Institute of Medicine. (2012). Accelerating Progress in Obesity Prevention: Solving the Weight of the Nation. Washington, DC: National Academies Press.

Jin, G.Z., \& Leslie, P. (2009). Reputational incentives for restaurant hygiene. American Economic Journal: Microeconomics, 237-267.

Kim, H. B., Lee, S. A., \& Lim, W. (2019). Knowing is not half the battle: Impacts of information from the National Health Screening Program in Korea. Journal of Health Economics, 65, 1-14.

Kolstad, J. T. (2013). Information and quality when motivation is intrinsic: Evidence from surgeon report cards. American Economic Review, 103(7), 2875-2910. 
Pauly, M. V. (1968). The economics of moral hazard: Comment. American Economic Review, 58, 531-537.

Pope, D.G. (2009). Reacting to rankings: evidence from “America's Best Hospitals”. Journal of Health Economics, 28, 1154-1165.

Prina, S., \& Royer, H. (2014). The importance of parental knowledge: Evidence from weight report cards in Mexico. Journal of Health Economics, 37, 232-247.

Remler, D. K., \& Van Ryzin, G. G. (2014). Research methods in practice: Strategies for description and causation, 2nd Edition. Thousand Oaks, CA: Sage Publications.

Rice, T. (2013). The behavioral economics of health and health care. Annual Review of Public Health, 34, 431-447.

Roberto, C. A., Larsen, P. D., Agnew, H., Baik, J., \& Brownell, K. D. (2010). Evaluating the impact of menu labeling on food choices and intake. American Journal of Public Health, 100(2), 312-318.

Royer, H., Stehr, M., \& Sydnor, J. (2015). Incentives, commitments, and habit formation in exercise: Evidence from a field experiment with workers at a fortune-500 company. American Economic Journal: Applied Economics, 7, 51-84.

Saksena, Michelle J., Abigail M. Okrent, Tobenna D. Anekwe, Clare Cho, Christopher Dicken, Anne Effland, Howard Elitzak, Joanne Guthrie, Karen S. Hamrick, Jeffrey Hyman, Young Jo, Biing-Hwan Lin, Lisa Mancino, Patrick W. McLaughlin, Ilya Rahkovsky, Katherine Ralston, Travis A. Smith, Hayden Stewart, Jessica Todd, and Charlotte Tuttle. America’s Eating Habits: Food Away From Home, EIB-196, Michelle Saksena, Abigail M. Okrent, and Karen S. Hamrick, eds. U.S. Department of Agriculture, Economic Research Service, September 2018.

Shadish, W. R., Cook, T. D., \& Campbell, D. T. (2002). Experimental and Quasi-Experimental Designs for Generalized Causal Inference. Boston: Houghton Mifflin.

Simon, H. A. (1955). A behavioral model of rational choice. Quarterly Journal of Economics, 69(1), 99-118.

Spence, M. (1973). Job market signaling. Quarterly Journal of Economics, 87, 355-374.

Stewart, Hayden. Jeffrey Hyman and Diansheng Dong. 2014. Menu Labeling Imparts New Information About the Calorie Content of Restaurant Foods, ERR-179, U.S. Department of Agriculture, Economic Research Service, December 2014.

Stigler, G. J. (1961). The economics of information. Journal of Political Economy, 69(3), 213225.

Taksler, G. B., \& Elbel, B. (2014). Calorie labeling and consumer estimation of calories purchased. International Journal of Behavioral Nutrition and Physical Activity, 11(1), 91.

Thunström, L., Nordström, J., Shogren, J.F., Ehmke, M., \& van’t Veld, K. (2016). Strategic selfignorance. Journal of Risk and Uncertainty, 52, 117-136.

U.S. Census. 2020a. United States Census QuickFacts. https://www.census.gov/quickfacts/fact/table/US/PST045218

U.S. Census. 2020b. United States Census tables on educational attainment. https://data.census.gov/cedsci/table?q=education\&hidePreview=false\&tid=ACSST1Y201 8.S1501\&t=Education\&vintage $=2018$

Variyam, J.N. (2008). Do nutrition labels improve dietary outcomes?. Health Economics, 17, 695-708.

World Health Organization. (2000). Obesity: Preventing and managing the global epidemic. Geneva, Switzerland: World Health Organization. 
Figure 1: Recruitment Flow Chart for Randomized Controlled Field Experiment in Restaurant

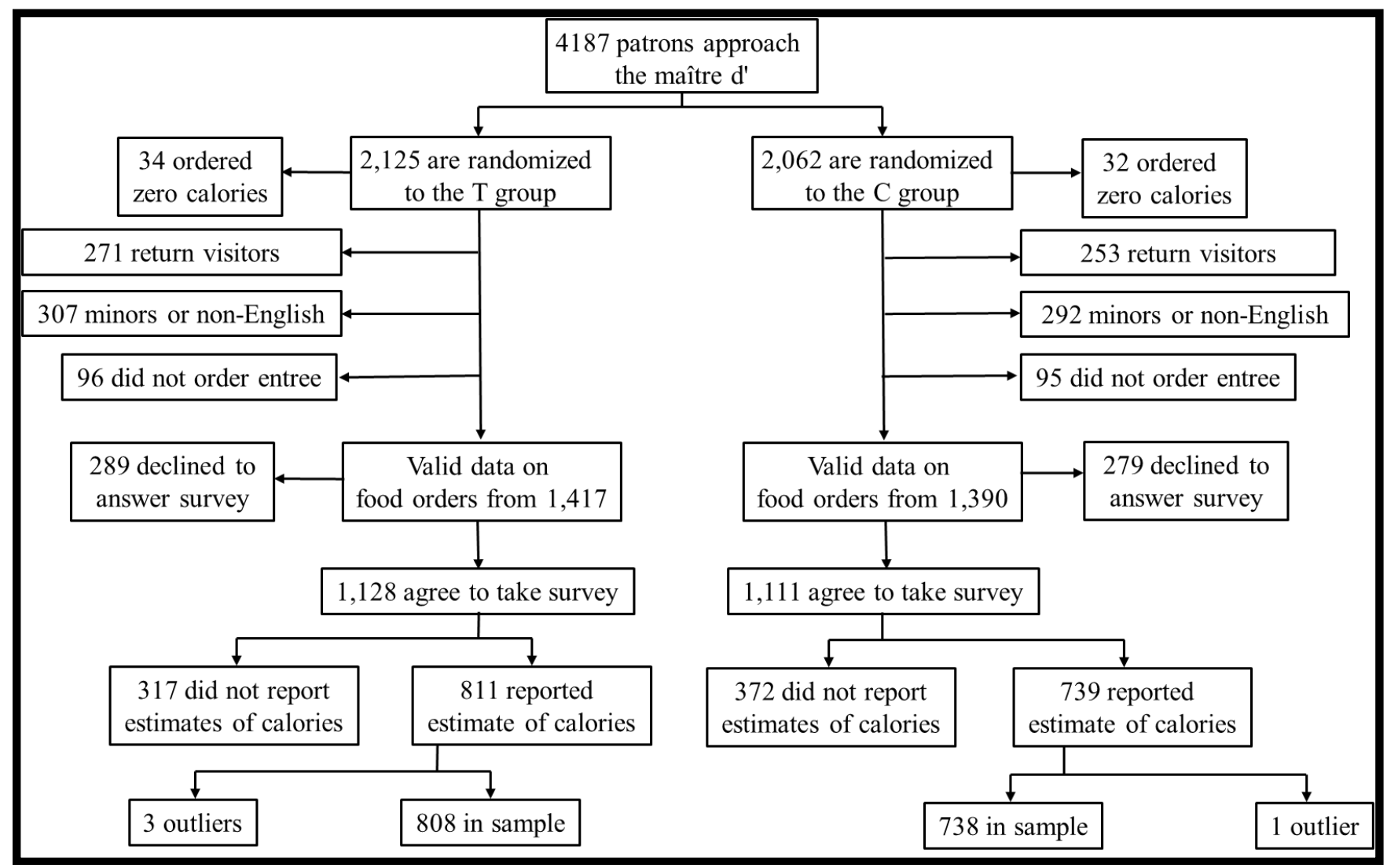

Note: The four outliers in the sample were reports of calories ordered of 12; 30; 10,000; and 15,000. Given that the next lowest report was 100 , and the next highest report was 5,000, these outliers were interpreted as errors rather than true beliefs. 
Figure 2: Accuracy in absence of Calorie Labels (i.e. control group only)

Distribution of Actual and Estimated Ordered Calories

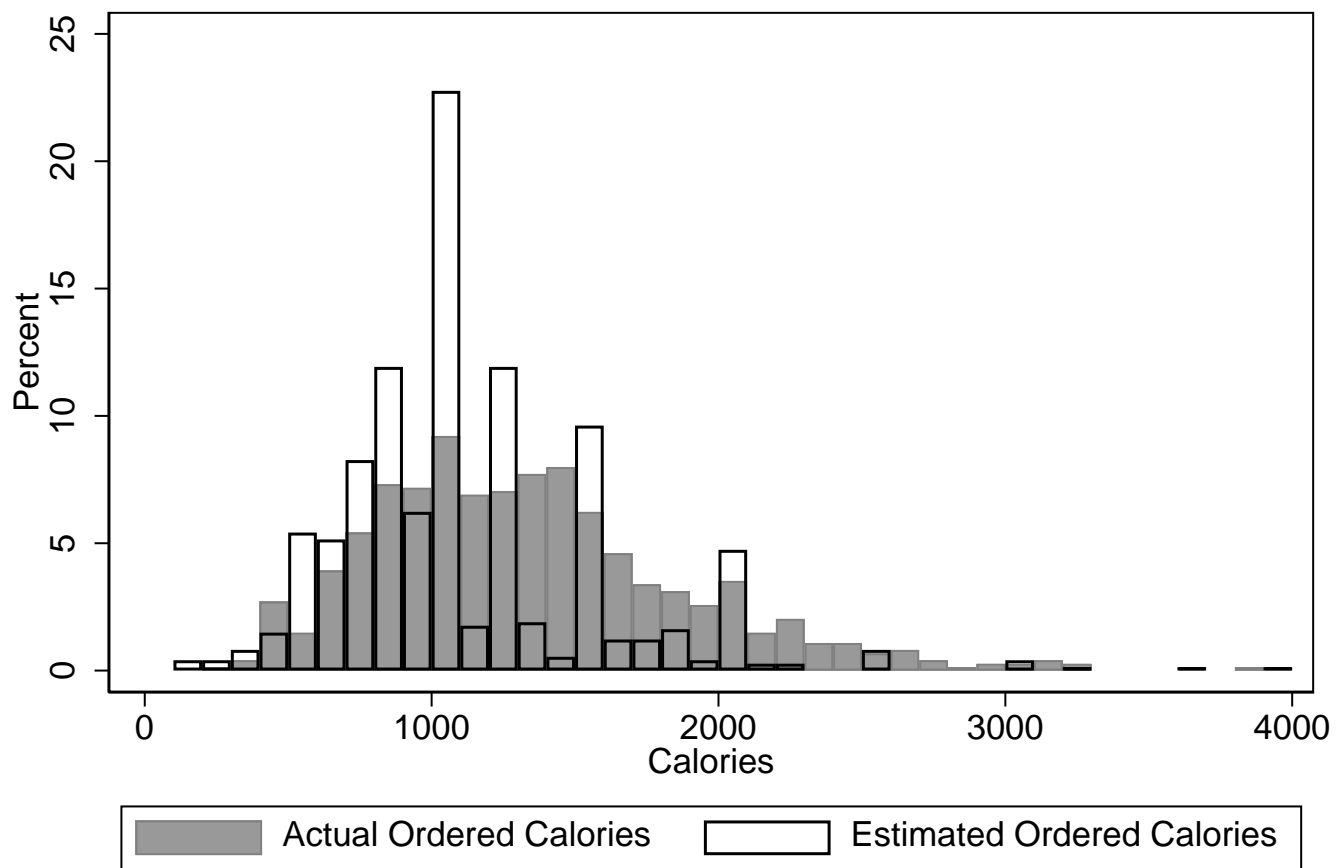


Figure 3: Raw Error and Actual Calories Ordered

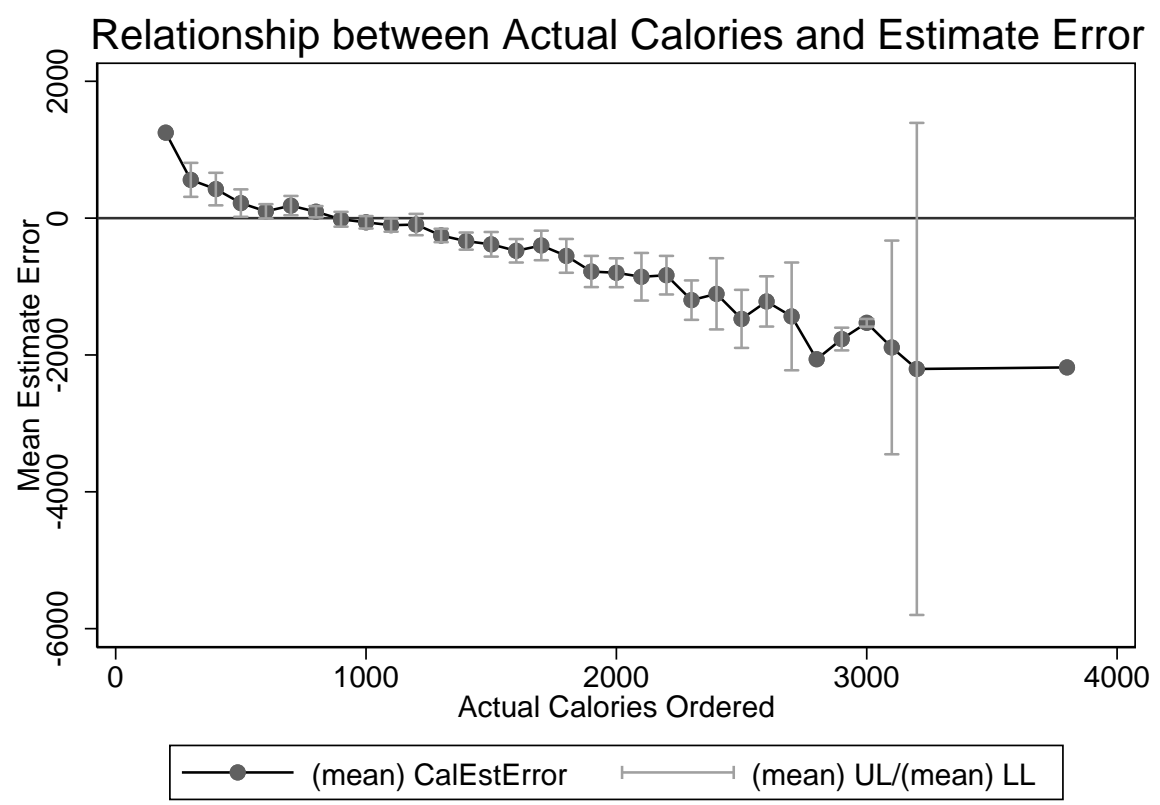

Note: Actual Calories Ordered bin size is 100. There are 429 unique values for Actual Calories Ordered. Bars 95\% CI, omitted if SE undefined.

Figure 4: Percent Raw Error and Actual Calories Ordered

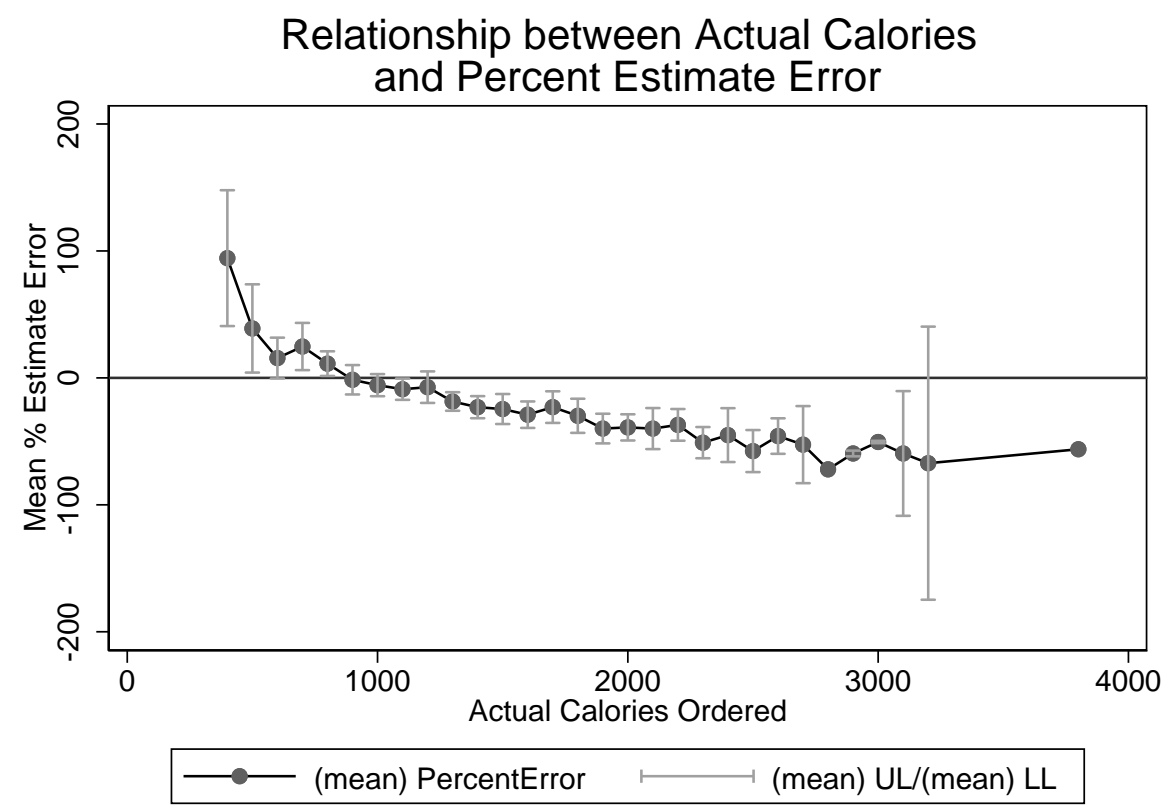

Note: Actual Calories Ordered bin size is 100 . There are 429 unique values for Actual Calories Ordered. Bars 95\% CI, omitted if SE undefined. 
Table 1: Summary Statistics of Consumer Characteristics

\begin{tabular}{|c|c|c|c|c|}
\hline & Full Sample & Control & Treated & Difference \\
\hline \multirow[t]{3}{*}{ Male } & 0.456 & 0.461 & 0.451 & 0.01 \\
\hline & $(0.498)$ & $(0.499)$ & $(0.498)$ & $(0.025)$ \\
\hline & $\mathrm{N}=1543$ & $\mathrm{~N}=736$ & $\mathrm{~N}=807$ & $\mathrm{p}$-value $=0.689$ \\
\hline \multirow[t]{3}{*}{ Age } & 41.312 & 41.198 & 41.416 & -0.218 \\
\hline & (17.703) & $(17.72)$ & (17.699) & $(0.907)$ \\
\hline & $\mathrm{N}=1526$ & $\mathrm{~N}=731$ & $\mathrm{~N}=795$ & $\mathrm{p}$-value $=0.810$ \\
\hline \multirow[t]{3}{*}{ Hispanic } & 0.065 & 0.063 & 0.068 & -0.005 \\
\hline & $(0.247)$ & $(0.243)$ & $(0.251)$ & $(0.013)$ \\
\hline & $\mathrm{N}=1533$ & $\mathrm{~N}=733$ & $\mathrm{~N}=800$ & $\mathrm{p}$-value $=0.701$ \\
\hline \multirow[t]{3}{*}{ White } & 0.730 & 0.726 & 0.733 & -0.007 \\
\hline & $(0.444)$ & $(0.446)$ & $(0.443)$ & $(0.023)$ \\
\hline & $\mathrm{N}=1536$ & $\mathrm{~N}=734$ & $\mathrm{~N}=802$ & $\mathrm{p}$-value $=0.761$ \\
\hline \multirow[t]{3}{*}{ Asian } & 0.187 & 0.191 & 0.183 & 0.007 \\
\hline & (0.39) & $(0.393)$ & $(0.387)$ & $(0.02)$ \\
\hline & $\mathrm{N}=1536$ & $\mathrm{~N}=734$ & $\mathrm{~N}=802$ & $\mathrm{p}$-value $=0.726$ \\
\hline \multirow[t]{3}{*}{ Other Race } & 0.083 & 0.083 & 0.084 & 0.000 \\
\hline & $(0.276)$ & $(0.276)$ & $(0.277)$ & $(0.014)$ \\
\hline & $\mathrm{N}=1536$ & $\mathrm{~N}=734$ & $\mathrm{~N}=802$ & p-value $>0.999$ \\
\hline \multirow[t]{3}{*}{ Less Than College } & 0.113 & 0.109 & 0.118 & -0.009 \\
\hline & $(0.317)$ & $(0.311)$ & $(0.323)$ & $(0.016)$ \\
\hline & $\mathrm{N}=1542$ & $\mathrm{~N}=737$ & $\mathrm{~N}=805$ & $\mathrm{p}$-value $=0.574$ \\
\hline \multirow[t]{3}{*}{ Current College } & 0.176 & 0.186 & 0.168 & 0.018 \\
\hline & $(0.381)$ & $(0.389)$ & $(0.374)$ & (0.019) \\
\hline & $\mathrm{N}=1542$ & $\mathrm{~N}=737$ & $\mathrm{~N}=805$ & $\mathrm{p}$-value $=0.343$ \\
\hline \multirow{3}{*}{$\begin{array}{l}\text { College Grad } \\
\text { or Grad Student }\end{array}$} & 0.257 & 0.258 & 0.256 & 0.002 \\
\hline & $(0.437)$ & $(0.438)$ & $(0.437)$ & $(0.022)$ \\
\hline & $\mathrm{N}=1542$ & $\mathrm{~N}=737$ & $\mathrm{~N}=805$ & $\mathrm{p}$-value $=0.928$ \\
\hline \multirow[t]{3}{*}{ Grad Degree } & 0.453 & 0.448 & 0.458 & -0.011 \\
\hline & (0.498) & $(0.498)$ & $(0.499)$ & $(0.025)$ \\
\hline & $\mathrm{N}=1542$ & $\mathrm{~N}=737$ & $\mathrm{~N}=805$ & $\mathrm{p}$-value $=0.660$ \\
\hline \multirow[t]{3}{*}{ Party Size } & 3.545 & 3.356 & 3.717 & -0.36 \\
\hline & (1.953) & (1.678) & $(2.161)$ & (0.099) \\
\hline & $\mathrm{N}=1546$ & $\mathrm{~N}=738$ & $\mathrm{~N}=808$ & $\mathrm{p}$-value $<0.001$ \\
\hline
\end{tabular}


Table 2: Summary Statistics of Outcomes

\begin{tabular}{|c|c|c|c|c|}
\hline \multirow{4}{*}{$\begin{array}{l}\text { Absolute Value of Error } \\
\text { of Estimate }\end{array}$} & Full Sample & Control & Treated & Difference \\
\hline & 464.98 & 497.02 & 435.72 & 61.31 \\
\hline & $(420.52)$ & $(435.26)$ & $(404.64)$ & $(21.36)$ \\
\hline & $\mathrm{N}=1546$ & $\mathrm{~N}=738$ & $\mathrm{~N}=808$ & p-value $<0.01$ \\
\hline \multirow{3}{*}{$\begin{array}{l}\text { Percent Absolute Value } \\
\text { of Error }\end{array}$} & 35.84 & 37.66 & 34.17 & 3.50 \\
\hline & (34.39) & $(37.58)$ & (31.13) & $(1.75)$ \\
\hline & $\mathrm{N}=1546$ & $\mathrm{~N}=738$ & $\mathrm{~N}=808$ & $p$-value $=0.05$ \\
\hline \multirow[t]{3}{*}{ Underestimate by more than $50 \%$} & 0.13 & 0.14 & 0.11 & 0.03 \\
\hline & $(0.33)$ & $(0.35)$ & $(0.32)$ & $(0.02)$ \\
\hline & $\mathrm{N}=1546$ & $\mathrm{~N}=738$ & $\mathrm{~N}=808$ & $p$-value $=0.08$ \\
\hline \multirow[t]{3}{*}{ Underestimate by $25-49 \%$} & 0.28 & 0.30 & 0.25 & 0.05 \\
\hline & $(0.45)$ & $(0.46)$ & $(0.44)$ & $(0.02)$ \\
\hline & $\mathrm{N}=1546$ & $\mathrm{~N}=738$ & $\mathrm{~N}=808$ & $p$-value $=0.03$ \\
\hline \multirow[t]{3}{*}{ Underestimate by $10-24 \%$} & 0.15 & 0.15 & 0.16 & 0.00 \\
\hline & $(0.36)$ & $(0.36)$ & $(0.36)$ & $(0.02)$ \\
\hline & $\mathrm{N}=1546$ & $\mathrm{~N}=738$ & $\mathrm{~N}=808$ & $p$-value $=0.88$ \\
\hline \multirow[t]{3}{*}{ Less than $10 \%$ off from true value } & 0.17 & 0.16 & 0.18 & -0.02 \\
\hline & $(0.37)$ & $(0.36)$ & $(0.39)$ & $(0.02)$ \\
\hline & $\mathrm{N}=1546$ & $\mathrm{~N}=738$ & $\mathrm{~N}=808$ & $\mathrm{p}$-value $=0.19$ \\
\hline \multirow[t]{3}{*}{ Overestimate by $10-24 \%$} & 0.08 & 0.08 & 0.09 & -0.01 \\
\hline & $(0.28)$ & $(0.26)$ & $(0.29)$ & $(0.01)$ \\
\hline & $\mathrm{N}=1546$ & $\mathrm{~N}=738$ & $\mathrm{~N}=808$ & $\mathrm{p}$-value $=0.35$ \\
\hline \multirow{3}{*}{ Overestimate by $25-49 \%$} & 0.09 & 0.06 & 0.11 & -0.05 \\
\hline & $(0.28)$ & $(0.24)$ & $(0.31)$ & $(0.01)$ \\
\hline & $\mathrm{N}=1546$ & $\mathrm{~N}=738$ & $\mathrm{~N}=808$ & $\mathrm{p}$-value $<0.01$ \\
\hline \multirow{3}{*}{ Overestimate by more than $50 \%$} & 0.10 & 0.10 & 0.09 & 0.01 \\
\hline & $(0.30)$ & $(0.31)$ & $(0.29)$ & $(0.02)$ \\
\hline & $\mathrm{N}=1546$ & $\mathrm{~N}=738$ & $\mathrm{~N}=808$ & $\mathrm{p}$-value $=0.50$ \\
\hline \multirow[t]{3}{*}{ Absolute Value of Error $<5 \%$} & 0.09 & 0.08 & 0.09 & -0.01 \\
\hline & $(0.28)$ & $(0.28)$ & $(0.29)$ & $(0.01)$ \\
\hline & $\mathrm{N}=1546$ & $\mathrm{~N}=738$ & $\mathrm{~N}=808$ & $\mathrm{p}$-value $=0.59$ \\
\hline \multirow[t]{3}{*}{ Absolute value of error $5-24 \%$} & 0.32 & 0.30 & 0.34 & -0.03 \\
\hline & $(0.47)$ & $(0.46)$ & $(0.47)$ & $(0.02)$ \\
\hline & $\mathrm{N}=1546$ & $\mathrm{~N}=738$ & $\mathrm{~N}=808$ & $\mathrm{p}$-value $=0.16$ \\
\hline \multirow[t]{3}{*}{ Absolute value of error $25-49 \%$} & 0.36 & 0.36 & 0.37 & 0.00 \\
\hline & $(0.48)$ & $(0.48)$ & $(0.48)$ & $(0.02)$ \\
\hline & $\mathrm{N}=1546$ & $\mathrm{~N}=738$ & $\mathrm{~N}=808$ & $\mathrm{p}$-value $=0.89$ \\
\hline \multirow[t]{3}{*}{ Absolute value of error $>=50 \%$} & 0.23 & 0.25 & 0.21 & 0.04 \\
\hline & $(0.42)$ & $(0.43)$ & $(0.41)$ & $(0.02)$ \\
\hline & $\mathrm{N}=1546$ & $\mathrm{~N}=738$ & $\mathrm{~N}=808$ & $p$-value $=0.06$ \\
\hline \multirow[t]{3}{*}{ Actual Calories Ordered } & 1308.12 & 1340.6 & 1278.45 & 62.15 \\
\hline & $(538.59)$ & $(544.05)$ & $(532.15)$ & (27.39) \\
\hline & $\mathrm{N}=1546$ & $\mathrm{~N}=738$ & $\mathrm{~N}=808$ & $\mathrm{p}$-value $=0.02$ \\
\hline \multirow[t]{3}{*}{ Estimated Calories Ordered } & 1093.29 & 1079.86 & 1105.56 & -25.70 \\
\hline & $(466.49)$ & $(463.52)$ & $(469.14)$ & (23.75) \\
\hline & $\mathrm{N}=1546$ & $\mathrm{~N}=738$ & $\mathrm{~N}=808$ & $p$-value $=0.28$ \\
\hline
\end{tabular}


Table 3: Descriptive Statistics Outcomes

\begin{tabular}{|c|c|c|c|c|c|c|}
\hline \multicolumn{7}{|c|}{ Panel A: Control Group Only } \\
\hline & Mean & SD & Min & Max & P-value & $\mathrm{N}$ \\
\hline Absolute Value of Error & 497 & 435 & 0 & 2490 & $<0.001$ & 738 \\
\hline Percent Absolute Value of Error & 37.7 & 37.6 & 0.0 & 500.0 & $<0.001$ & 738 \\
\hline Underestimate by more than $50 \%$ & 0.144 & 0.351 & 0 & 1 & $<0.001$ & 738 \\
\hline Underestimate by $25-49 \%$ & 0.302 & 0.460 & 0 & 1 & $<0.001$ & 738 \\
\hline Underestimate by $10-24 \%$ & 0.153 & 0.360 & 0 & 1 & $<0.001$ & 738 \\
\hline Less than $10 \%$ off from true value & 0.156 & 0.363 & 0 & 1 & $<0.001$ & 738 \\
\hline Overestimate by $10-24 \%$ & 0.076 & 0.265 & 0 & 1 & $<0.001$ & 738 \\
\hline Overestimate by $25-49 \%$ & 0.060 & 0.237 & 0 & 1 & $<0.001$ & 738 \\
\hline Overestimate by more than $50 \%$ & 0.104 & 0.306 & 0 & 1 & $<0.001$ & 738 \\
\hline Absolute Value of Error $<5 \%$ & 0.083 & 0.276 & 0 & 1 & $<0.001$ & 738 \\
\hline Absolute value of error $5-24 \%$ & 0.302 & 0.460 & 0 & 1 & $<0.001$ & 738 \\
\hline Absolute value of error $25-49 \%$ & 0.362 & 0.481 & 0 & 1 & $<0.001$ & 738 \\
\hline Absolute value of error $>=50 \%$ & 0.248 & 0.432 & 0 & 1 & $<0.001$ & 738 \\
\hline Actual Calories Ordered & 1341 & 544 & 250 & 3881 & $<0.001$ & 738 \\
\hline Estimated Calories Ordered & 1080 & 464 & 100 & 4000 & $<0.001$ & 738 \\
\hline See Calories & 0.156 & 0.363 & 0 & 1 & $<0.001$ & 730 \\
\hline \multicolumn{7}{|c|}{ Panel B: Treated Group Only } \\
\hline & Mean & $\mathrm{SD}$ & Min & Max & P-value & $\mathrm{N}$ \\
\hline Absolute Value of Error & 436 & 405 & 0 & 3010 & $<0.001$ & 808 \\
\hline Percent Absolute Value of Error & 34.2 & 31.1 & 0.0 & 304.0 & $<0.001$ & 808 \\
\hline Underestimate by more than $50 \%$ & 0.114 & 0.318 & 0 & 1 & $<0.001$ & 808 \\
\hline Underestimate by $25-49 \%$ & 0.254 & 0.435 & 0 & 1 & $<0.001$ & 808 \\
\hline Underestimate by $10-24 \%$ & 0.156 & 0.363 & 0 & 1 & $<0.001$ & 808 \\
\hline Less than $10 \%$ off from true value & 0.181 & 0.385 & 0 & 1 & $<0.001$ & 808 \\
\hline Overestimate by $10-24 \%$ & 0.089 & 0.285 & 0 & 1 & $<0.001$ & 808 \\
\hline Overestimate by $25-49 \%$ & 0.111 & 0.315 & 0 & 1 & $<0.001$ & 808 \\
\hline Overestimate by more than $50 \%$ & 0.094 & 0.292 & 0 & 1 & $<0.001$ & 808 \\
\hline Absolute Value of Error $<5 \%$ & 0.090 & 0.287 & 0 & 1 & $<0.001$ & 808 \\
\hline Absolute value of error $5-24 \%$ & 0.335 & 0.472 & 0 & 1 & $<0.001$ & 808 \\
\hline Absolute value of error $25-49 \%$ & 0.365 & 0.482 & 0 & 1 & $<0.001$ & 808 \\
\hline Absolute value of error $>=50 \%$ & 0.208 & 0.406 & 0 & 1 & $<0.001$ & 808 \\
\hline Actual Calories Ordered & 1278 & 532 & 340 & 4200 & $<0.001$ & 808 \\
\hline Estimated Calories Ordered & 1106 & 469 & 100 & 5000 & $<0.001$ & 808 \\
\hline See Calories & 0.826 & 0.380 & 0 & 1 & $<0.001$ & 797 \\
\hline
\end{tabular}


Table 4: Effect of Menu Labeling on Seeing Labels

\begin{tabular}{cccc}
\hline & Model 1 & Model 2 & Model 3 \\
\hline See Calories & $0.669^{* * *}$ & $0.688^{* * *}$ & $0.688^{* * *}$ \\
Mean=0.506 & $(0.025)$ & $(0.026)$ & $(0.026)$ \\
& $\mathrm{N}=1527$ & $\mathrm{~N}=1527$ & $\mathrm{~N}=1527$ \\
\hline
\end{tabular}

$* \mathrm{p}<0.10, * * \mathrm{p}<0.05, * * * \mathrm{p}<0.01$

Standard errors in parentheses (se); clustered at the party level.

Model 1 covariates: treated.

Model 2 covariates: as above, day of week FE, month FE, table FE, seat FE, server FE and party size.

Model 3 covariates: as above, gender, age, Hispanic, race, and education.

Table 5: Effect of Menu Labeling on Knowledge

\begin{tabular}{cccc}
\hline & Model 1 & Model 2 & Model 3 \\
\cline { 2 - 4 } Absolute Value of Error of Estimate & $-61.306^{* *}$ & $-64.379^{* *}$ & $-64.669^{* *}$ \\
Mean=464.983 & $(24.814)$ & $(27.038)$ & $(26.821)$ \\
& $\mathrm{N}=1546$ & $\mathrm{~N}=1546$ & $\mathrm{~N}=1546$ \\
Percent Absolute Value of Error & $-3.500^{*}$ & $-4.027^{* *}$ & $-3.998^{* *}$ \\
Mean=35.836 & $(1.805)$ & $(1.712)$ & $(1.709)$ \\
& $\mathrm{N}=1546$ & $\mathrm{~N}=1546$ & $\mathrm{~N}=1546$ \\
Actual Calories Ordered & $-62.149^{*}$ & -45.149 & -48.604 \\
Mean=1308.122 & $(36.126)$ & $(38.466)$ & $(37.029)$ \\
& $\mathrm{N}=1546$ & $\mathrm{~N}=1546$ & $\mathrm{~N}=1546$ \\
Estimated Calories Ordered & 25.702 & 47.238 & 46.699 \\
Mean=1093.289 & $(27.783)$ & $(30.067)$ & $(29.151)$ \\
& $\mathrm{N}=1546$ & $\mathrm{~N}=1546$ & $\mathrm{~N}=1546$ \\
\hline
\end{tabular}

$* \mathrm{p}<0.10, * * \mathrm{p}<0.05, * * * \mathrm{p}<0.01$

Standard errors in parentheses (se); clustered at the party level.

Model 1 covariates: treated.

Model 2 covariates: as above, day of week FE, month FE, table FE, seat FE, server FE and party size.

Model 3 covariates: as above, gender, age, Hispanic, race, and education. 
Table 6A: Effect of Menu Labeling on Knowledge, Overestimates and Underestimates

\begin{tabular}{cccc} 
& Model 1 & Model 2 & Model 3 \\
\cline { 2 - 4 } Underestimate by more than $50 \%$ & -0.030 & $-0.038^{*}$ & $-0.037 *$ \\
Mean $=0.128$ & $(0.019)$ & $(0.021)$ & $(0.021)$ \\
Underestimate by $25-49 \%$ & $\mathrm{~N}=1546$ & $\mathrm{~N}=1546$ & $\mathrm{~N}=1546$ \\
Mean $=0.277$ & $-0.048^{* *}$ & $-0.052^{* *}$ & $-0.057^{* *}$ \\
& $(0.023)$ & $(0.025)$ & $(0.025)$ \\
Underestimate by 10-24\% & $\mathrm{N}=1546$ & $\mathrm{~N}=1546$ & $\mathrm{~N}=1546$ \\
Mean $=0.155$ & 0.003 & 0.008 & 0.009 \\
& $(0.018)$ & $(0.020)$ & $(0.020)$ \\
Less than $10 \%$ off from true value & $\mathrm{N}=1546$ & $\mathrm{~N}=1546$ & $\mathrm{~N}=1546$ \\
Mean $=0.169$ & 0.025 & $0.039 *$ & $0.039 *$ \\
& $(0.020)$ & $(0.021)$ & $(0.021)$ \\
Overestimate by $10-24 \%$ & $\mathrm{~N}=1546$ & $\mathrm{~N}=1546$ & $\mathrm{~N}=1546$ \\
Mean $=0.083$ & 0.013 & 0.011 & 0.012 \\
& $(0.014)$ & $(0.015)$ & $(0.015)$ \\
Overestimate by $25-49 \%$ & $\mathrm{~N}=1546$ & $\mathrm{~N}=1546$ & $\mathrm{~N}=1546$ \\
Mean=0.087 & $0.052^{* * *}$ & $0.057 * * *$ & $0.058^{* * *}$ \\
& $(0.014)$ & $(0.017)$ & $(0.017)$ \\
Overestimate by more than $50 \%$ & $\mathrm{~N}=1546$ & $\mathrm{~N}=1546$ & $\mathrm{~N}=1546$ \\
Mean=0.099 & -0.01 & -0.02 & -0.02 \\
& $(0.015)$ & $(0.016)$ & $(0.016)$ \\
& $\mathrm{N}=1546$ & $\mathrm{~N}=1546$ & $\mathrm{~N}=1546$ \\
\hline
\end{tabular}

$* \mathrm{p}<0.10, * * \mathrm{p}<0.05, * * * \mathrm{p}<0.01$

Standard errors in parentheses (se); clustered at the party level.

Model 1 covariates: treated.

Model 2 covariates: as above, day of week FE, month FE, table FE, seat FE, server FE and party size.

Model 3 covariates: as above, gender, age, Hispanic, race, and education. 
Table 6B: Effect of Menu Labeling on Knowledge, Different Ranges of Absolute Value of Error

\begin{tabular}{cccc}
\hline & Model 1 & Model 2 & Model 3 \\
\cline { 2 - 4 } Absolute Value of Error $<5 \%$ & 0.008 & 0.011 & 0.011 \\
Mean=0.087 & $(0.015)$ & $(0.016)$ & $(0.016)$ \\
& $\mathrm{N}=1546$ & $\mathrm{~N}=1546$ & $\mathrm{~N}=1546$ \\
Absolute value of error 5-24\% & 0.033 & $0.047^{*}$ & $0.049^{*}$ \\
Mean=0.320 & $(0.025)$ & $(0.026)$ & $(0.026)$ \\
& $\mathrm{N}=1546$ & $\mathrm{~N}=1546$ & $\mathrm{~N}=1546$ \\
Absolute value of error $25-49 \%$ & 0.003 & 0.004 & 0.002 \\
Mean=0.364 & $(0.024)$ & $(0.027)$ & $(0.027)$ \\
& $\mathrm{N}=1546$ & $\mathrm{~N}=1546$ & $\mathrm{~N}=1546$ \\
Absolute value of error $>=50 \%$ & $-0.040^{*}$ & $-0.058^{* *}$ & $-0.057 * *$ \\
Mean=0.227 & $(0.022)$ & $(0.024)$ & $(0.024)$ \\
& $\mathrm{N}=1546$ & $\mathrm{~N}=1546$ & $\mathrm{~N}=1546$ \\
\hline
\end{tabular}

$* \mathrm{p}<0.10, * * \mathrm{p}<0.05, * * * \mathrm{p}<0.01$

Standard errors in parentheses (se); clustered at the party level.

Model 1 covariates: treated.

Model 2 covariates: as above, day of week FE, month FE, table FE, seat FE, server FE and party size.

Model 3 covariates: as above, gender, age, Hispanic, race, and education. 
Table 7: Relationship between Accuracy and Covariates (Control and Treated Groups)

\begin{tabular}{lccc}
\hline & $\begin{array}{c}\text { See Calorie Labels } \\
\text { (Treated Only) }\end{array}$ & $\begin{array}{c}\text { Absolute Value of } \\
\text { Error }\end{array}$ & $\begin{array}{c}\text { Absolute Value of } \\
\text { Percent Error }\end{array}$ \\
\hline Male & $-0.057^{* *}$ & $64.371^{* * *}$ & $2.846^{*}$ \\
& $(0.028)$ & $(19.397)$ & $(1.609)$ \\
Age & 0.000 & 1.043 & $0.125^{*}$ \\
& $(0.001)$ & $(0.864)$ & $(0.075)$ \\
Hispanic & -0.016 & -60.489 & -4.010 \\
& $(0.060)$ & $(39.654)$ & $(4.441)$ \\
Asian & -0.061 & -11.617 & $4.280^{* *}$ \\
& $(0.045)$ & $(27.962)$ & $(2.036)$ \\
Other Race & $-0.169^{* * *}$ & 44.028 & 4.895 \\
& $(0.065)$ & $(40.340)$ & $(3.164)$ \\
Race Missing & $0.183^{* *}$ & 64.626 & 43.325 \\
& $(0.080)$ & $(123.893)$ & $(46.417)$ \\
Less Than College & -0.015 & 23.329 & 3.291 \\
& $(0.045)$ & $(43.943)$ & $(2.729)$ \\
Current College & -0.030 & $-81.096 * *$ & 1.508 \\
& $(0.051)$ & $(39.088)$ & $(2.975)$ \\
Grad Degree & -13.220 & 1.680 \\
& -0.030 & $(28.956)$ & $(2.131)$ \\
Education Missing & $(0.032)$ & -110.325 & -24.160 \\
& -0.173 & $(172.083)$ & $(15.906)$ \\
Party Size & $(0.347)$ & -8.616 & -0.140 \\
& -0.013 & $(5.445)$ & $(0.432)$ \\
Tuesday & $(0.010)$ & 10.297 & 0.035 \\
& 0.018 & $(49.265)$ & $(3.713)$ \\
Wednesday & -2.318 & 0.652 \\
& $(0.068)$ & $(48.007)$ & $(3.443)$ \\
Thursday & -0.014 & -55.293 & $(3.395$ \\
& $(0.079)$ & $(42.545)$ & -0.839 \\
Friday & -0.005 & 25.069 & $(3.342)$ \\
& $(0.065)$ & $(46.606)$ & $(3.950$ \\
Saturday & -0.021 & $(47.126$ & 1.528 \\
& $(0.065)$ & -22.701 & $(4.615)$ \\
Sunday & 0.016 & $(49.281)$ & 1546 \\
& $(0.074)$ & 464.983 & \\
Mean & 0.024 & 1546 & \\
$\mathrm{~N}$ & $(0.067)$ & & 0.826 \\
\hline
\end{tabular}

${ }^{*} \mathrm{p}<0.10,{ }^{* *} \mathrm{p}<0.05,{ }^{* * *} \mathrm{p}<0.01$

Standard errors in parentheses (se); clustered at the party level.

Missing gender, missing age, missing Hispanic, white, college grad/grad student, Monday are omitted from the table. 
Table 8A: Heterogeneous Treatment Effects by Education

\begin{tabular}{|c|c|c|c|c|}
\hline & $\begin{array}{c}\text { Absolute } \\
\text { Value of Error } \\
\text { of Est }\end{array}$ & $\begin{array}{l}\text { \% Absolute } \\
\text { Value of } \\
\text { Error } \\
\end{array}$ & $\begin{array}{c}\text { Actual } \\
\text { Calories } \\
\text { Ordered } \\
\end{array}$ & $\begin{array}{c}\text { Estimated } \\
\text { Calories } \\
\text { Ordered } \\
\end{array}$ \\
\hline $\begin{array}{l}\text { Treated } \mathrm{x} \\
\text { Less Than College }\end{array}$ & $\begin{array}{l}-115.624 \\
(73.359)\end{array}$ & $\begin{array}{l}-5.569 \\
(4.841)\end{array}$ & $\begin{array}{l}-50.941 \\
(87.096)\end{array}$ & $\begin{array}{c}16.168 \\
(80.712)\end{array}$ \\
\hline Treated & $\begin{array}{l}-49.992 * \\
(28.571) \\
\end{array}$ & $\begin{array}{l}-3.310^{*} \\
(1.828)\end{array}$ & $\begin{array}{l}-41.253 \\
(39.375) \\
\end{array}$ & $\begin{array}{c}45.288 \\
(30.292) \\
\end{array}$ \\
\hline $\begin{array}{l}\mathrm{N} \\
\text { Mean }\end{array}$ & $\begin{array}{c}1542 \\
465.076\end{array}$ & $\begin{array}{c}1542 \\
35.856\end{array}$ & $\begin{array}{c}1542 \\
1307.904\end{array}$ & $\begin{array}{c}1542 \\
1093.628\end{array}$ \\
\hline
\end{tabular}

Standard errors in parentheses (se); clustered at the party level.

Covariates: treated, treated-by-graduate education, day of week FE, month FE, table FE, seat FE, server FE, party size, gender, age, Hispanic, race, and education.

Treated * Less Than College equals 1 if respondent is treated and has less than high school, high school graduate, or some college (excluding current college student); 0 otherwise.

Table 8B: Heterogeneous Treatment Effects by Education (cont.)

\begin{tabular}{|c|c|c|c|c|c|c|c|}
\hline & \multicolumn{3}{|c|}{ Underestimate } & \multirow{2}{*}{$\begin{array}{l}\text { Less than } \\
10 \% \text { off from } \\
\text { true value }\end{array}$} & \multicolumn{3}{|c|}{ Overestimate } \\
\hline & $\begin{array}{c}\text { More than } \\
50 \%\end{array}$ & $25-49 \%$ & $10-24 \%$ & & $10-24 \%$ & $25-49 \%$ & $\begin{array}{l}\text { More than } \\
50 \%\end{array}$ \\
\hline $\begin{array}{l}\text { Treated } \\
\quad * \text { Less Than College }\end{array}$ & $\begin{array}{l}-0.079 \\
(0.058)\end{array}$ & $\begin{array}{c}0.031 \\
(0.077)\end{array}$ & $\begin{array}{c}0.020 \\
(0.055)\end{array}$ & $\begin{array}{c}0.056 \\
(0.062)\end{array}$ & $\begin{array}{l}-0.036 \\
(0.043)\end{array}$ & $\begin{array}{c}0.037 \\
(0.049)\end{array}$ & $\begin{array}{l}-0.036 \\
(0.052)\end{array}$ \\
\hline Treated & $\begin{array}{l}-0.028 \\
(0.023)\end{array}$ & $\begin{array}{c}-0.059 * * \\
(0.026)\end{array}$ & $\begin{array}{c}0.006 \\
(0.021)\end{array}$ & $\begin{array}{c}0.033 \\
(0.023)\end{array}$ & $\begin{array}{c}0.016 \\
(0.016)\end{array}$ & $\begin{array}{c}0.054^{* * *} \\
(0.018)\end{array}$ & $\begin{array}{l}-0.015 \\
(0.017) \\
\end{array}$ \\
\hline $\mathrm{N}$ & 1542 & 1542 & 1542 & 1542 & 1542 & 1542 & 1542 \\
\hline Mean & 0.128 & 0.276 & 0.154 & 0.169 & 0.083 & 0.087 & 0.099 \\
\hline
\end{tabular}

$* \mathrm{p}<0.10,{ }^{* *} \mathrm{p}<0.05,{ }^{* * *} \mathrm{p}<0.01$

Standard errors in parentheses (se); clustered at the party level.

Covariates: treated, treated-by-graduate education, day of week FE, month FE, table FE, seat FE, server FE, party

size, gender, age, Hispanic, race, and education.

Treated * Less Than College equals 1 if respondent is treated and has less than high school, high school graduate, or some college (excluding current college student); 0 otherwise. 
Table 8C: Heterogeneous Treatment Effects by Education (cont.)

\begin{tabular}{lcccc}
\hline & $\begin{array}{c}\text { Absolute Value of } \\
\text { Error }<5 \%\end{array}$ & $\begin{array}{c}\text { Absolute value of } \\
\text { error 5-24\% }\end{array}$ & $\begin{array}{c}\text { Absolute value of } \\
\text { error 25-49\% }\end{array}$ & $\begin{array}{c}\text { Absolute value of } \\
\text { error }>=50 \%\end{array}$ \\
\cline { 2 - 5 } Treated & 0.011 & 0.029 & 0.068 & -0.115 \\
* Less Than College & $(0.048)$ & $(0.079)$ & $(0.081)$ & $(0.073)$ \\
Treated & 0.009 & 0.045 & -0.005 & $-0.043^{*}$ \\
& $(0.017)$ & $(0.028)$ & $(0.028)$ & $(0.026)$ \\
N & 1542 & 1542 & 1542 & 1542 \\
Mean & 0.087 & 0.319 & 0.363 & 0.228 \\
\hline
\end{tabular}

${ }^{*} \mathrm{p}<0.10,{ }^{* *} \mathrm{p}<0.05,{ }^{* * *} \mathrm{p}<0.01$

Standard errors in parentheses (se); clustered at the party level.

Covariates: treated, treated-by-graduate education, day of week FE, month FE, table FE, seat FE, server FE, party size, gender, age, Hispanic, race, and education.

Treated * Less Than College equals 1 if respondent is treated and has less than high school, high school graduate, or some college (excluding current college student); 0 otherwise. 